\section{New leaflet for reporting} concerns

The GDC has launched a new leaflet advising the public on how to report concerns about a dental professional's fitness to practise. The leaflet 'How to report a dental professional to us' explains what patients should do if they are worried that a dental professional is unfit to work because of their skills, health or behaviour; how to report concerns to the GDC; and what will happen as a result.

The leaflet is available to download from the GDC website www.gdc-uk.org. Copies can also be requested from the GDC Communications department on 020 70092784 or by email at communications @gdc-uk.org.

\section{Finalists revealed}

The Dental Defence Union (DDU) has announced the names of the outstanding teachers and trainers who have reached the final of the 2007 DDU Educational Awards. The finalists, selected from a shortlist of nominees, will be competing in three different categories at the award ceremony this month in London.

The two finalists in the category of DCP Teacher of the Year are Jane Holt from the Leeds Dental Institute and Judy Fraser from the School of Professionals Complementary to Dentistry, Portsmouth.

Head of the DDU, Rupert Hoppenbrouwers said, 'We feel it is important to publicly recognise the nominees' achievements.'

The finalists in all the award categories will compete for the titles in front of a selected audience of dental academics and professionals at the awards ceremony. Finalists will be judged across a number of criteria, including knowledge of the subject, enthusiasm and ability to motivate. Winners and runners-up will be awarded $£ 250$ each and the overall winners in each category will receive $£ 1,000$ towards the cost of educational materials for their schools or VT schemes. In addition to the main sponsor, Dentsply, the awards are also supported by the BDA.

\title{
Success for orthodontic nurses
}

Three orthodontic nurses were presented with awards at this year's annual British Orthodontic Conference which took place in Harrogate. Hayley Stout won the 3M Unitek Dental Nurse of the Year award with her presentation An extended nursing role or are we just taking the pics? while Anita Curly won the TOC sponsored award for the best presentation of a topic in folder form with her presentation Orthodontic risk management: A review of DHE Services.

The British Orthodontic Society Award to an Orthodontic Nurse for Distinguished Service went to Mary Bardet from York District Hospital, who is also the membership secretary of the ONG.

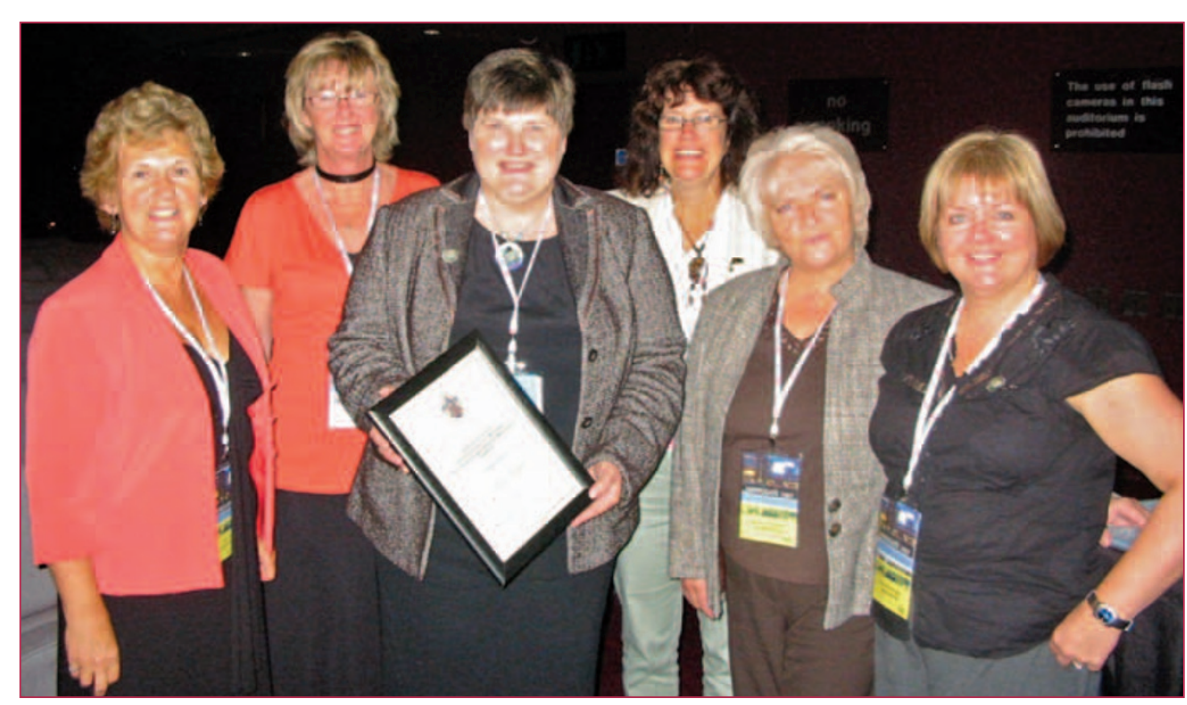

Mary Bardet (with her certificate) being congratulated by other orthodontic nurses

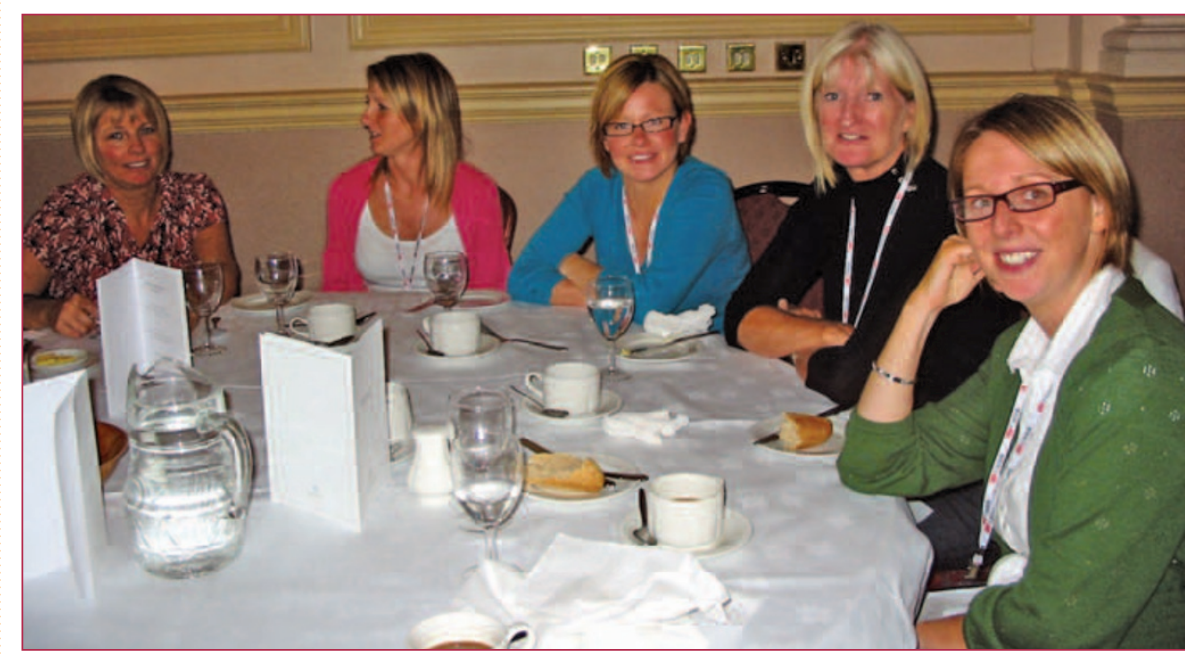

Nurses enjoying lunch
The Orthodontic National Group for Dental Nurses and Therapists (ONG) is an organisation affiliated to the British Orthodontic Society. The awards were presented during the ONG's dedicated one day Nurses Programme.

Around 400 orthodontic nurses attended the programme which featured lectures on functional appliances, bonded retention, facial mapping and intra-oral distraction.

Orthodontic dental nurses are encouraged to attend the Conference and are eligible to attend lectures on all four days.

This year marks the centenary of the founding of the first of the five British Orthodontic Societies. These were amalgamated in 1994 to become the British Orthodontic Society. 